\title{
Correlation of Clinical Depression, Anxiety and Academic Performance of Adolescents in Selected Secondary Schools in Kenya
}

\author{
Moureen Adhiambo Nyayieka ${ }^{1, *}$, Stella Kemuma Nyagwencha ${ }^{2}$, Solomon Nzyuko ${ }^{3}$ \\ ${ }^{1}$ Department of Psychology and Counseling, Daystar University, Nairobi, Kenya \\ ${ }^{2}$ Department of Psychology, United States International University, Nairobi, Kenya \\ ${ }^{3}$ Institute of Leadership and Professional Development, Daystar University, Nairobi, Kenya
}

\section{Email address:}

maureenobuya@hotmail.com (M. A. Nyayieka), stenyagwencha@yahoo.com (S. K. Nyagwencha), sznyuko@daystar.ac.ke (S. Nzyuko) ${ }^{*}$ Corresponding author

\section{To cite this article:}

Moureen Adhiambo Nyayieka, Stella Kemuma Nyagwencha, Solomon Nzyuko. Correlation of Clinical Depression, Anxiety and Academic Performance of Adolescents in Selected Secondary Schools in Kenya. American Journal of Applied Psychology.

Vol. 9, No. 1, 2020, pp. 14-21. doi: 10.11648/j.ajap.20200901.13

Received: February 18, 2020 Accepted: February 28, 2020; Published: March 6, 2020

\begin{abstract}
Depression and anxiety are associated with lower academic performance among adolescents. In Kenya, up to $26.4 \%$ of school going adolescents have been reported to present with symptoms of depression and anxiety. This study aimed at testing the correlation between academic performance, clinical depression and anxiety among adolescents in selected secondary schools in Homabay County, Kenya. In a quasi-experimental study, nonequivalent pretest-posttest design was adopted to test correlation between clinical depression, anxiety and academic performance among the adolescents. Two schools were selected with one being the experimental group and the other being the control group. Data was collected from 126 adolescents who were screened for depression and anxiety symptoms using Beck Depression Inventory (BDI-II), Beck Anxiety Inventory (BAI) and researcher generated questionnaire. Respondents aged 14-16 were 54\% (68) while those aged 17-19 were $46 \%$ (58). In order to examine the relationship between depression and anxiety, and academic performance, bivariate analysis was employed. Spearman Correlation Coefficient was used to show correlation between depression, anxiety and academic performance. The study found that the correlation test between $Y_{1}$ (depression) and $\mu \mathrm{X}$ (academic performance) using Distance Correlation Coefficient indicated a significant correlation $(\mathrm{p}=0.010)$. However, the correlation test between $\mathrm{Y}_{2}$ (anxiety) and $\mu \mathrm{X}$ (academic performance) was not significant $(\mathrm{p}=0.651)$. Moreover, $\mu \mathrm{X}$ (academic performance) was also used as predictor to test the dependence of $Y_{1}$ (depression) and $Y_{2}$ (Anxiety) in correlation. Depression and anxiety were found to correlate with academic performance which should be treated as a clinical concern for mental health service providers and secondary school heads.
\end{abstract}

Keywords: Depression, Anxiety, Academic Performance, Adolescents, Correlation, Selected Secondary Schools, Kenya

\section{Introduction}

Academic performance is defined as the extent to which an adolescent student or an institution accomplishes specific educational goals [9]. Performance often depends on the indicators used in measuring it such as examinations or continuous assessment, procedural knowledge such as skills as well as curricular based criteria like grades [25]. Psychological disorders such as depression and anxiety often put pressure on adolescent students to perform better in academics [22].

Performance in academic lifecycle of an adolescent demand all facets of mental well-being including psychological, social, emotional, spiritual and physical wellbeing [12]. Unidentified and untreated depressive symptoms are associated with decreased psychosocial functioning, poor academic performance or school drop-out, increased risk for substance abuse, other mental health issues, and increased suicidal thoughts, attempts and completion [26].

Numerous studies have indicated that mental issues like 
depression and anxiety negatively interfere with academic performance [5]. Few mental health studies have tried to bridge the gap between the relationship on depression and anxiety to academic performance [18]. However, these disorders collaboratively interfere with adolescent performance in school resulting to low academic achievement [17].

In a study that was conducted in government schools at Mahasamund district of Chhattisgarh among 120 high school students aged 16 years, depression, anxiety and academic achievement were found to have significant positive association [22]. This meant that depression and anxiety affected students' academic performance. Several documented factors have influence on adolescent academic performance [7]. These include factors such as classroom environment [23], depression and anxiety, as well as teacher support [20]. Likewise, certain characteristics of adolescents and their family such as parent's education contribute to the problem [21].

Adolescent depression and anxiety has also been linked to high parental expectations [14]. This is because adolescents internalize their parents' expectations which in turn contribute to unnecessary academic pressure and eventually failing in school [16]. Besides, there are limited resources for mental health treatment to assist adolescents' manage their level of depression and anxiety [22].

Adolescents who experience higher levels of anxiety suffer a lot in school since higher levels of anxiety has further destructive outcomes on academic attainment thus, can result to lower academic performance and poor working memory [12]. This is because of the fact that school responsibilities that include extra working memory are significantly interfered with. Poor performance is also associated with reduced school presence and undesirable behavior [16]. Besides, adolescents with anxiety suffer greater chances of dropping out of school and not being ambitious about higher education, when likened to the ordinary population [5].

Consequently, adolescents who experience symptoms of depression have difficulty with school work and relationship with parents and peers, as well as decreased interest and involvement in daily activities and responsibilities [16]. This is because depressed adolescent often spend less time on homework hence achieve lower grade point averages. These adolescents also tend to have health complaints such as fatigue, abdominal pain and headaches [11].

Depression and anxiety experienced in academic field are considered common psychosocial disorders in school going adolescents [17]. However, when these disorders are experienced in higher levels, they raise concerns which require intervention of mental health professionals [5]. On account of the forgoing, it is significant that education stakeholders, national policy makers such as the Ministry of Education and the Kenya Institute of Curriculum Development, teachers and mental health professionals take initiative to deal with psychological concerns among adolescent, as well as create awareness and educate adolescents on the disorders [19].

\section{Methods}

\subsection{Sample}

In this quasi-experimental study, nonequivalent pretestposttest method was adopted to test correlation between clinical depression, anxiety and academic performance among the adolescents. The pretest-posttest method was significant as it incorporated the research objectives, with a 3-month and 6-month follow-up to evaluate the effects of the symptoms of depression and anxiety on academic performance, as well as determine if a specific treatment influences an outcome. This study was conducted in two purposely selected secondary schools among 126 adolescents who were screened for depression and anxiety symptoms, of which 54\% (68) of the respondents were aged $14-16$ and $46 \%$ (58) were aged 17-19. One school was designated as for treatment while other school was for control. Confounder variables were controlled by asking the school administration not to introduce any other counseling services for the period this study was to be conducted in the selected schools. The selected schools are located in Homabay County in western Kenya.

The students in these schools are both day scholars and boarders. Most of the students in these schools fall in the age bracket of 14 to 19 years which is the adolescence stage [27]. The researcher worked with students in form one, two and form three aged between 14-19 years and included both boys and girls. Form four students were not considered since they were quite busy preparing for their final year national examinations. The students who participated in this study possessed almost similar characteristics since they were categorized as coming from the same developmental stage. Parents and guardians gave consent on behalf of students who were below 18 years.

Subsequently, adolescents who met the criteria for mild and moderate symptoms of depression and anxiety according to the [2] were included in the study. Adolescents who tested positive for severe depression and anxiety were excluded from the study and those who met the criteria for severe depression and anxiety were referred for psychiatric intervention. Additionally, those with history of intellectual challenge were restricted from participating in the study. One adolescent with self-reported history of psychosis symptoms due to another medical condition was excluded from the study. Those who objected to participate as a result of their religious and personal reasons were also excluded from the study. During the interventions, any adolescent who appeared in less than three intervention sessions and failed to complete assessments at the baseline, midline and endline were excluded from the study.

\subsection{Procedure and Methods}

Respondents were divided in groups of 12 and 13 which was suitable for conducting assessments. These were distributed in each group with the help of research assistants who read the questions to the respondents as well as clarified 
questions which were difficult to understand. The researchers ensured that all respondents were at par before proceeding to the next question.

\subsubsection{Socio-demographic Information}

The Socio Demographic Questionnaire (SDQ) was the researcher's designed tool comprising of closed and openended questions. This captured characteristics such as age, gender, class level, whether they were boarders or day scholars, religion, family setup, relationship with other students in school, at home and other relevant information.

\subsubsection{Depression}

Depression symptoms were assessed using Beck's Depression Inventory-II (BDI-II). This instrument is a 21item self-reporting questionnaire, ranked 0 (symptoms absent) to 3 (severe symptoms) used in assessing the severity of depression among normal and psychiatric population in the preceding two weeks [6]. For individuals who have been clinically tested, scores of 0 to 13 show minimal depression; scores of 14 to 17 indicate mild depression; 18 to 28 demonstrate moderate level of depression while 29 to 63 indicates severe symptoms of depression in an individual. This is according to the American Psychological Association included in the diagnostic criteria included in the Diagnostic and Statistical Manual for Mental Disorders [2].

Additionally, [6] reported that mean correlation coefficient 0.72 and 0.60 had been found between clinical ratings of depression and the BDI-II for psychiatric and nonpsychiatric populations. In a study that was conducted among 783 Iranian adolescents, BDI-II was found to be effective in treatment of depression. The study which comprised of 433 boys and 350 girls, demonstrated that adolescents have a myriad of issues which can be resolved using the BDI instrument for assessing depression [13].

\subsubsection{Anxiety}

Similarly, anxiety symptoms were assessed using Beck's Anxiety Inventory (BAI) which consists of 21 questions with each response being scored on a scale value of 0 (not at all) to 3 (severely). Higher total scores is often an indication of severe symptoms of anxiety. According to [8], a grand sum between $0-9$ indicates normal to minimal anxiety, 10-18 indicates mild anxiety, 19-29 shows moderate anxiety, while a grand sum that exceeds 30 is a potential cause for concern. BAI has an internal consistency of Cronbach's alpha $=0.92$ with a one week test-retest reliability of BAI $=0.75$ [4].

\subsubsection{Academic Questionnaire}

The academic record questionnaire was the researcher generated tool which helped in assessing students' performance at baseline, midline and endline. Data collected from the respondents were analyzed using descriptive statistics with SPSS version 23.

\subsubsection{Data Analysis}

Data was analyzed using the descriptive statistics calculated for measures at the pre-test or post-test stage of experimental design. Measures of variability were employed such as the range and standard deviation to show how typical scores differed from the mean of a group of scores, and included bivariate analysis. In order to examine the relationship between depression and anxiety, and academic performance, the researcher employ the bivariate analysis. Spearman Correlation Coefficient was used to show correlation between the variables. The strength of relationships was also expressed using the Spearman calculation. This was valuable for making predictions with the $p$-value set at $p<0.05,95 \%$ confidence interval.

\section{Results}

Table 1. Frequency of Key Demographic Characteristics of the Study Respondents.

\begin{tabular}{ll}
\hline Variables & Frequency\% \\
\hline Respondent's Gender & $50(39.7)$ \\
Male & $76(60.3)$ \\
Female & \\
Respondent's Age & $68(54.0)$ \\
$14-16$ & $58(46.0)$ \\
$17-19$ & \\
Respondent's level of education & $46(36.5)$ \\
Form 1 & $41(32.5)$ \\
Form 2 & $39(30.7)$ \\
Form 3 & \\
Respondent's mode of study & $68(54.0)$ \\
Boarders & $58(46.0)$ \\
Day Scholars & \\
Respondent's Family Set-up & $71(56.3)$ \\
Both biological parents living together & $6(4.8)$ \\
Living with step parents & $5(4.0)$ \\
Parents separated & $1(.8)$ \\
Parents divorced & $30(23.8)$ \\
Single parents & $13(10.3)$ \\
Living with guardian &
\end{tabular}

Table 1 presents the distribution of the key sociodemographic characteristics to the study group. In regard to gender distribution, frequency of female respondents was higher at $60.3 \%$ (76) compared to male respondents at $39.7 \%$ (50). Further, the distribution of age showed that the frequency of respondents aged 14-16 was higher at 54\% (68) as opposed to respondents aged $17-19$ at $46 \%$ (58). In terms of respondent's level of education, the frequency of respondents in form 1 was slightly higher at $36.5 \%$ (46) compared to form $232.5 \%$ (41) and form $330.7 \%$ (39). Concerning respondent's mode of study, the frequency of boarders was more $54 \%$ (68) compared to the day scholars $46 \%$ (58). In light of respondent's family set-up, the frequency of respondents who lived with both biological parents was much higher at $56.3 \%$ (71) compared to respondents with single parents $23.8 \%$ (30), living with guardians were $10.3 \%$ (13), step parents $4.8 \%$ (6), parents separated $4 \%$ (5) and parents divorced $0.8 \%$ (1). 
Table 2. Bivariate Analysis of Respondent's Depression and the Socio-Demographic.

\begin{tabular}{|c|c|c|c|c|c|c|c|}
\hline \multirow[t]{2}{*}{ Variables } & \multirow[t]{2}{*}{ Total } & \multicolumn{3}{|c|}{ Respondent's scores on Depression } & \multicolumn{3}{|c|}{ Chi-Square Test } \\
\hline & & Minimal & Mild & Moderate & Value & Df & Sig. \\
\hline \multicolumn{8}{|l|}{ Respondent's Gender } \\
\hline Male & $50(39.7)$ & $1(0.8)$ & $18(14.3)$ & $31(24.6)$ & 12.387 & 1 & $.002 *$ \\
\hline Female & $76(60.3)$ & $0(0.0)$ & $9(7.1)$ & $67(53.2)$ & & & \\
\hline \multicolumn{8}{|l|}{ Respondent's Age } \\
\hline $14-16$ & $68(54.0)$ & $0(0.0)$ & $16(12.7)$ & $52(41.3)$ & 1.509 & 1 & .470 \\
\hline $17-19$ & $58(46.0)$ & $1(0.8)$ & $11(8.7)$ & $46(36.5)$ & & & \\
\hline Form 1 & $46(36.5)$ & $0(0.0)$ & $15(11.9)$ & $31(24.6)$ & 7.638 & 2 & .106 \\
\hline Form 2 & $41(32.5)$ & $0(0.0)$ & $7(5.6)$ & $34(27.0)$ & & & \\
\hline Form 3 & $39(31.0)$ & $1(0.8)$ & $5(4.0)$ & $33(26.2)$ & & & \\
\hline \multicolumn{8}{|l|}{ Respondent's Mode of Study } \\
\hline Border Scholar & $68(54.0)$ & $0(0.0)$ & $19(51.1)$ & $49(38.9)$ & 4.718 & 1 & .095 \\
\hline Day Scholar & $58(46.0)$ & $1(0.8)$ & $8(6.3)$ & $49(38.9)$ & & & \\
\hline Living with step parents & $6(4.8)$ & $0(0.0)$ & $3(2.4)$ & $3(2.4)$ & & & \\
\hline Parents separated & $5(4.0)$ & $0(0.0)$ & $1(0.8)$ & $4(3.2)$ & & & \\
\hline Parents divorced & $1(0.8)$ & $0(0.0)$ & $0(0.0)$ & $1(0.8)$ & & & \\
\hline Single parents & $30(23.8)$ & $0(0.0)$ & $3(2.4)$ & $27(21.4)$ & & & \\
\hline Living with Guardian & $13(10.3)$ & $0(0.0)$ & $3(2.4)$ & $10(7.9)$ & & & \\
\hline
\end{tabular}

Table 2 presents bivariate analysis of respondent's depression and the socio-demographic factors. The Table shows that significant numbers of female respondents scored higher on moderate depression compared to other levels of depression at $53.2 \%$ (67) compared to male counterpart at $24.6 \%$ (31). However, in terms of mild depression, male respondents scored higher at $14.3 \%$ (18) compared to female scores at $7.1 \%$ (9).
Statistical analysis indicated that the difference in distribution of gender and scores on depression at baseline was significant $(\mathrm{p}=0.002)$. As shown in Table 2, respondents age $(\mathrm{p}=0.0470)$, level of education $(\mathrm{p}=0.106)$, mode of study $(\mathrm{p}=0.095)$ and family set-up $(p=0.757)$ were distributed insignificantly. This seems to imply that gender being the only variable that was significantly distributed plays a controlling factor in this regard.

Table 3. Bivariate Analysis of Respondent's Anxiety and the Socio-Demographic Factors.

\begin{tabular}{|c|c|c|c|c|c|c|}
\hline \multirow[t]{2}{*}{ Variable } & \multirow[t]{2}{*}{ Total\% } & \multicolumn{2}{|c|}{ Respondent's scores on Anxiety } & \multicolumn{3}{|c|}{ Chi-Square Test } \\
\hline & & Mild & Moderate & Value & Df & Sig. \\
\hline \multicolumn{7}{|l|}{ Respondent's Gender } \\
\hline Male & $50(39.7)$ & $20(15.9)$ & $30(23.8)$ & 1.272 & 1 & .259 \\
\hline Female & $76(39.7)$ & $23(15.9)$ & $53(42.1)$ & & & \\
\hline \multicolumn{7}{|l|}{ Respondent's Age } \\
\hline $14-16$ & $68(54.0)$ & $22(17.5)$ & $46(36.5)$ & .207 & 1 & .649 \\
\hline $17-19$ & $58(46.0)$ & $21(16.7)$ & $37(29.4)$ & & & \\
\hline Form 1 & $46(36.5)$ & $21(16.7)$ & $25(19.8)$ & 4.643 & 2 & .098 \\
\hline Form 2 & $41(32.5)$ & $10(7.9)$ & $31(24.6)$ & & & \\
\hline Form 3 & $39(31.0)$ & $12(9.5)$ & $27(21.4)$ & & & \\
\hline \multicolumn{7}{|l|}{ Respondent's Mode of Study } \\
\hline Border Scholar & $68(54.0)$ & $21(16.7)$ & $47(37.3)$ & .692 & 1 & .406 \\
\hline Day Scholar & $58(46.0)$ & $22(17.5)$ & $36(28.6)$ & & & \\
\hline \multicolumn{7}{|l|}{ Respondent's Family set-up } \\
\hline Living with step parents & $6(4.8)$ & $4(3.2)$ & $2(1.6)$ & & & \\
\hline Parents separated & $5(4.0)$ & $3(2.4)$ & $2(1.6)$ & & & \\
\hline Parents divorced & $1(0.8)$ & $0(0.0)$ & $1(0.8)$ & & & \\
\hline Single parents & $30(23.8)$ & $11(8.7)$ & $19(15.1)$ & & & \\
\hline Living with Guardian & $13(10.3)$ & $5(4.0)$ & $8(6.3)$ & & & \\
\hline
\end{tabular}

Table 3 presents bivariate analysis of respondent's anxiety and the socio-demographic factors. The Table shows that frequency of moderate anxiety among female respondents was higher at $42.1 \%$ (53) compared to male respondents at $23.8 \%(30)$. The frequency of mild anxiety was equally distributed among the gender at $39.7 \%$; males (50) and females (76). The Chi-square test indicated that there was no significant difference in the distribution scores on anxiety among the respondent's gender $(p=0.259)$. In addition, the frequency of anxiety and the socio-demographic characteristics in terms of respondent's age $(p=0.0649)$, level of education $(p=0.098)$, mode of study $(p=0.406)$ and family 
set-up ( $\mathrm{p}=0.292)$ were statistically insignificant.

Table 4. Respondent's Academic Performance.

\begin{tabular}{lllll}
\hline Variables & Frequency & Percent & Mean & Std. Deviation \\
\hline E = Poor & 9 & 7.1 & & \\
D, D- = Weak & 38 & 29.9 & 1.6984 & .81260 \\
C, C+, C-, D+ = Average & 62 & 48.8 & & \\
B+, B, B- = Good & 16 & 12.6 & & \\
A, A- = Very Good & 1 & .8 & & \\
\hline
\end{tabular}

Table 4 presents respondent's academic performance. As respondents who performed very good at $0.8 \%$ (1), Good at indicated, frequency of average scores on academic $12.6 \%$ (16), Weak at $29.9 \%(38)$, and Poor at $7.1 \%(9)$. The performance was higher at $48.8 \%$ (62) compared with mean was (1.6984 \pm (SD:.81260)).

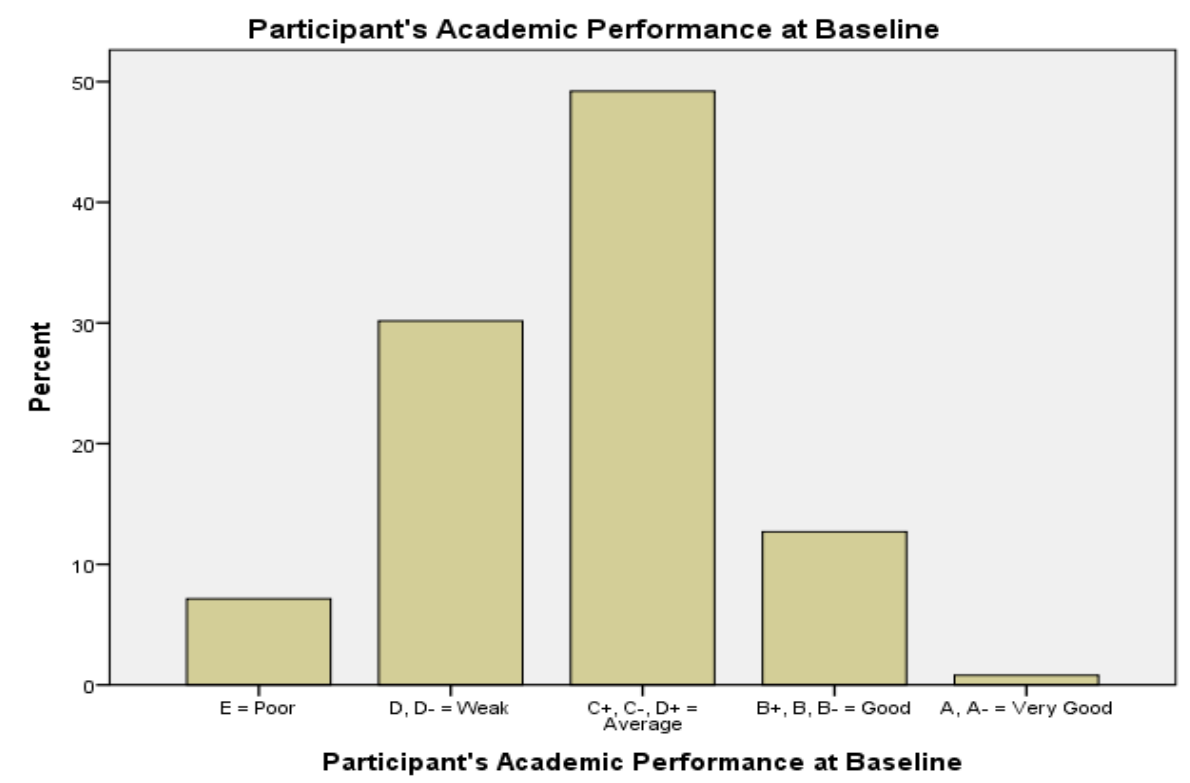

Figure 1. Respondent's Academic Performance.

Figure 1 shows the frequency in percentage of respondent's academic performance. As shown in the figure, respondents' whose performance were average scored higher.

Table 5. Distribution of Respondents' Academic Performance and Socio-Demographic Characteristics.

\begin{tabular}{|c|c|c|c|c|c|c|c|c|c|}
\hline \multirow{2}{*}{ Variable } & \multirow{2}{*}{ Total } & \multicolumn{5}{|c|}{ Academic Performance } & \multicolumn{3}{|c|}{ Chi-Square Test } \\
\hline & & E- Poor & Weak & Average & Good & Very Good & Value & Df & Sig. \\
\hline \multicolumn{10}{|l|}{ Respondent's Gender } \\
\hline Male & $50(39.7)$ & $3(2.4)$ & $11(8.7)$ & $29(23.0)$ & $6(4.8)$ & $1(0.8)$ & \multirow{3}{*}{4.836} & \multirow{2}{*}{1} & \multirow{2}{*}{.305} \\
\hline Female & $76(60.3)$ & $6(4.8)$ & $27(21.4)$ & $33(26.2)$ & $10(7.9)$ & $0(0.0)$ & & & \\
\hline \multicolumn{9}{|l|}{ Respondent's Age } & \\
\hline $14-16$ & $68(54.0)$ & $4(3.2)$ & $12(9.5)$ & $41(32.5)$ & $11(8.7)$ & $0(0.0)$ & \multirow{2}{*}{14.267} & \multirow[t]{2}{*}{1} & \multirow[t]{2}{*}{$.006^{*}$} \\
\hline $17-19$ & $58(46.0)$ & $5(4.0)$ & $26(20.6)$ & $21(16.7)$ & $5(4.0)$ & $1(0.8)$ & & & \\
\hline \multicolumn{10}{|c|}{ Respondent's level of education } \\
\hline Form 1 & $46(36.5)$ & $1(0.8)$ & $3(2.4)$ & $28(22.2)$ & $13(10.3)$ & $1(0.9)$ & \multirow[t]{3}{*}{35.821} & \multirow[t]{3}{*}{2} & \multirow[t]{3}{*}{$.000^{*}$} \\
\hline Form 2 & $41(32.5)$ & $5(4.0)$ & $15(11.9)$ & $19(15.1)$ & $2(1.6)$ & $0(0.0)$ & & & \\
\hline Form 3 & $39(31.0)$ & $3(2.4)$ & $20(15.9)$ & 15 (11.9) & $1(0.8)$ & $0(0.0)$ & & & \\
\hline \multicolumn{10}{|c|}{ Respondents mode of School } \\
\hline Boarders & $68(54.0)$ & $4(3.2)$ & $19(15.1)$ & $35(27.8)$ & $9(7.1)$ & $1(0.8)$ & \multirow[t]{4}{*}{1.610} & \multirow[t]{4}{*}{1} & \multirow[t]{4}{*}{.807} \\
\hline \multicolumn{7}{|l|}{ Day } & & & \\
\hline Scholars & $58(46.0)$ & $5(4.0)$ & $19(15.1)$ & $27(21.4)$ & $7(5.6)$ & $0(0.0)$ & & & \\
\hline \multicolumn{7}{|c|}{ Respondent's family set-up } & & & \\
\hline Both Parents living & $71(56.3)$ & $6(4.8)$ & $14(11.1)$ & $41(32.5)$ & $10(7.9)$ & $0(0.0)$ & 22.549 & 5 & .312 \\
\hline \multicolumn{10}{|l|}{ Together } \\
\hline Living with step parents & $6(4.8)$ & $1(0.8)$ & $4(3.2)$ & $1(0.8)$ & $0(0.0)$ & $0(0.0)$ & & & \\
\hline Parents separated & $5(4.0)$ & $0(0.0)$ & $1(0.8)$ & $3(2.4)$ & $1(0.8)$ & $0(0.0)$ & & & \\
\hline Parents divorced & $1(0.8)$ & $0(0.0)$ & $1(0.8)$ & $0(0.0)$ & $0(0.0)$ & $0(0.0)$ & & & \\
\hline Single Parents & $30(23.8)$ & $0(0.0)$ & $12(9.5)$ & $13(10.3)$ & $4(3.2)$ & $1(0.8)$ & & & \\
\hline Living with guardian & $13(10.3)$ & $2(1.6)$ & $6(4.8)$ & $4(3.2)$ & $1(0.8)$ & $0(0.0)$ & & & \\
\hline
\end{tabular}


Table 5 presents distribution of respondent's academic performance and socio-demographic characteristics. The table indicates that out of $39.7 \%$ (50) male respondents, $2.4 \%$ (3) were in the category for poor, $8.7 \%$ (11) weak, $23 \%$ (29) average, $4.8 \%$ (6) good and $0.8 \%$ (1) was very good. In regard to females, out of $60.3 \%$ (76) respondents, 4.8 (6) got poor results, $21.4 \%$ (27) weak, $26.4 \%$ (33) were average and $7.9 \%$ (10) were good. The difference in distribution of academic performance across gender were insignificant $(\mathrm{p}=0.305)$.

In relation to respondent's age and academic performance, out of 68 constituted $54 \%$ respondents aged 14-16, 3.2\% of the respondents scores were poor, $9.5 \%$ weak, $32.5 \%$ average and $8.7 \%$ good. In addition, out of $46 \%$ (58) respondents aged $17-19,4 \%$ of the respondents' performance were poor, $20.6 \%$ weak, $16.7 \%$ average, $4 \%$ good and $0.8 \%$ very good. In terms of respondent's level of education, out of 46 of those in form $136.5 \%$ of the respondents performance were poor at $0.8 \%, 2.4 \%$ weak, $22.2 \%$ average, $10.3 \%$ good and 0.9 very good. In a total of $32.5 \%$ (41) of respondents in form 2, performance was as follows; $4 \%$ were poor, $11.9 \%$ weak, $15.1 \%$ average and $1.6 \%$ good. In addition, $31 \%$ (39) of respondents in form 3 , achieved the following scores; $2.4 \%$ were poor, $15.9 \%$ weak, $11.9 \%$ average and $1 \%$ good. The statistical analysis showed that the difference in distribution of respondents' academic performance was statistically significant $(\mathrm{p}=0.000)$.

Table 6. Distance Correlation Coefficient Testing Correlation of Depression, Anxiety and Academic Performance of the Respondents.

\begin{tabular}{|c|c|c|c|c|c|}
\hline Control Variables & Mean /Std. Dev & Spearman Coefficient test & Depression & Anxiety & Academic Performance \\
\hline \multirow{4}{*}{$\begin{array}{l}\text { Respondent's Scores on } \\
\text { Depression }\end{array}$} & \multirow{4}{*}{$1.7698 \pm(\mathrm{SD}: .44114)$} & Correlation & 1.000 & .233 & .230 \\
\hline & & Significant $(2$ tailed $)$ & \multirow{2}{*}{0} & .009 & .010 \\
\hline & & Significant (2-tailed) & & 124 & 123 \\
\hline & & Df & & & \\
\hline \multirow{3}{*}{$\begin{array}{l}\text { Respondent's Scores on } \\
\text { Anxiety }\end{array}$} & \multirow{3}{*}{$1.65984 \pm(\mathrm{SD}: .47603)$} & Correlation & .233 & 1.000 & -.041 \\
\hline & & & .009 & \multirow{2}{*}{0} & .651 \\
\hline & & Significant (2-tailed) & 124 & & 124 \\
\hline \multirow{4}{*}{$\begin{array}{l}\text { Respondent's Scores on } \\
\text { Academic Performance }\end{array}$} & \multirow{4}{*}{$1.6984 \pm(\mathrm{SD}: .81260)$} & Correlation & .793 & .213 & 1.000 \\
\hline & & \multirow{2}{*}{ Significant (2-tailed) } & .000 & .055 & \\
\hline & & & 124 & 124 & 0 \\
\hline & & Df & & & \\
\hline
\end{tabular}

Table 6 presents the distance correlation coefficient test, to evaluate the existence of correlation and similarity of vectors between paired variables (depression and anxiety). This statistics was to determine to what extent the two variables co-vary with the vector (academic performance). In other words, the distance between vector $\mathrm{X}$ and $\mathrm{Y}_{1}$ : $\mathrm{Y}_{2}$ was tested using the distance correlation coefficient. This statistics tests the correlation of existence between vector (academic performance) and $Y_{1}$ (Depression) and $Y_{2}$ (Anxiety) where $\mu \mathrm{X}$ and $\mathrm{Y}_{1}: \mathrm{Y}_{2}$ are the standard deviations of $\mathrm{X}$ and $\mathrm{Y}$. The numerator of the equation which is called covariance of $X$ and $\mathrm{Y}$, and is the difference of between the mean of the product of $\mathrm{X}$ and $\mathrm{Y}$ subtracted from the product of the means. For instance, as it indicated on the Table, the mean depression $\left(\mathrm{Y}_{1}\right) 1.7698 \pm(\mathrm{SD}: .44114)$ was tested in distance correlation coefficient with $\left(\mathrm{Y}_{2}\right)$ mean anxiety $1.65984 \pm$ (SD:.47603). The results indicated that there was a correlating relationship between $Y_{1}$ and $Y_{2}(p=0.009)$. This implies that anxiety and depression are statistically correlated, which meant that there was a further relationship between the two.

Similarly, the table also shows the correlation test between $\mathrm{Y}_{1}$ (depression) and $\mu \mathrm{X}$ (academic performance) where the distance correlation in mean of depression $\left(\mathrm{Y}_{1}\right) 1.7698 \pm$ (SD:.44114) was tested with academic performance $(\mu \mathrm{X})$ mean $1.6984 \pm(\mathrm{SD}: .81260)$. The DCC test showed that there was a significant correlation in relationship between $Y_{1}$ (depression) and $\mu \mathrm{X}$ (academic performance $(\mathrm{p}=0.010)$. This suggests a significant relationship, that existence of respondents' depression affects the academic performance of the participants.

Further, the table indicates the correlation test between $\mathrm{Y}_{2}$ (anxiety) and $\mu \mathrm{X}$ (academic performance), where the distance correlation in mean of anxiety $\left(\mathrm{Y}_{2}\right) 1.65984 \pm$ (SD:.47603) was tested with academic performance $(\mu \mathrm{X})$ mean $1.6984 \pm(\mathrm{SD}: .81260)$. The distance correlation coefficient (DCC) test shows that there was no significant correlation in relationship between $\mathrm{Y}_{2}$ (Anxiety) and $\mu \mathrm{X}$ (academic performance $(\mathrm{p}=0.651)$. This implies that there was no significant relationship between anxiety and academic performance among the respondents.

Moreover, $\mu \mathrm{X}$ (academic performance) was also used as predictor to test the dependence of $\mathrm{Y}_{1}$ (depression) and $\mathrm{Y}_{2}$ (Anxiety) in correlation. The Table indicates that $\mu \mathrm{X}$ (academic performance) mean $1.6984 \pm$ (SD:.81260) was compared in distance correlation coefficient test with depression $\left(\mathrm{Y}_{1}\right) 1.7698 \pm(\mathrm{SD}: .44114)$. The results shows a significant correlation in relationship $(\mathrm{p}=0.000)$. This seems to suggest that academic performance of the participants can trigger depression. Also, $\mu \mathrm{X}$ (academic performance) mean $1.6984 \pm(\mathrm{SD}: .81260)$ was compared in distance correlation coefficient test with mean of anxiety $\left(\mathrm{Y}_{2}\right) \quad 1.65984 \pm$ (SD:.47603). The result also indicates that academic performance is a significant trigger of anxiety $(p=0.055)$.

\section{Discussion}

The study sought to examine the relationship between 
existence of depression and anxiety symptoms and academic performance. The results indicated that there was a correlation between anxiety and depression $(\mathrm{p}=0.009)$. Other studies have found that adolescents who display symptoms of depression and anxiety are predisposed in terms of cognitive distortions and unending worries which undermine academic performance [22]. The findings of this study were in line with the results of a study conducted among school going adolescents in the North of Iran. In this study, academic performance was analyzed as the dependent variable, and depression and anxiety as the independent variable [10]. Results indicated that depression and anxiety highly affected academic success $(r=-0.34$ and $\mathrm{r}=0.23, \mathrm{P} \leq 0.000)$. In a study conducted among Sudanese secondary school students, it was indicated that exam anxiety and depression positively correlated with academic performance (Coefficient of correlation $=0.752, p$ value $<0.000$ ), which showed that severity of depression was due to anxiety student encounter during exam period [3]. Further, the DCC test showed that there was a significant correlation in the relationship between depression and academic performance $(p=0.010)$. Similarly, when academic performance was used as predictor to test the dependence of depression and anxiety in correlation, the result showed that there was a significant correlation with depression $(\mathrm{p}=0.000)$. The findings obtained in this study are congruent with another study which pointed out that there was high correlation between depression $(1,156)$ $=4.770, \mathrm{p}<0.01$, anxiety $(1,157)=4.562, \mathrm{p}=<0.05$ and academic performance [22]. This meant that depression and anxiety disorders affected academic performance.

Therefore, there is need to scrutinize in depth what contributes to students developing symptoms of depression and anxiety thus interfering with the academic goals. The findings of this study also support the view that anxiety and depression affects students' academic achievement [16]. In Kenya, a study revealed statistically significant negative correlation when academic achievement was used as a predictor of anxiety [15], particularly when students were writing exams for the chemistry subject $(r=-.432, n=308$, $\mathrm{p}<.05$ ). In addition, the findings were also in concurrence with a study in India that revealed a significant negative relationship between anxiety disorder and academic performance $\mathrm{P}<.05$ [24].

Consequently, this study findings agrees with that which reported a significant correlation when academic performance was used as a predictor to test the dependence of anxiety and depression in correlation [1]. The results of this study will help in identifying students who show higher symptoms of depression and anxiety thus, facilitate early intervention to curb the disorders.

\section{Conclusion}

This study showed that adolescents in selected public secondary schools exhibit poor academic performance as a result of depression and anxiety. Thus, it is significant that depression and anxiety symptoms are identified early and prompt intervention offered to adolescents with heightened levels of these disorders. Further studies should point towards other psychosocial issues that could be acting as predictors to these disorders. Teachers should try to assist students from performing poorly by taking the necessary steps as well as creating conducive learning environment. Mental health service providers should work towards creating awareness in the community aimed at providing effective treatment plans to reduce the symptoms of depression and anxiety among this population. Further, adolescents should be encouraged to seek help early enough from mental health practitioners.

\section{Ethics}

Approval was sought from Daystar University Ethics and Review Board, Daystar University Department of Human and Social Sciences, National Council for Science and Technology in Kenya (NACOSTI) and head teachers' of the selected public secondary schools. Adolescents below 18 years provided assent while those aged 18 years and above provided informed consent.

\section{Conflict of Interest}

The authors declare that they have no conflict.

\section{Acknowledgements}

Research assistants Sarah Patricia Ngadi, Felix Omondi Ngar and Statistician Dr. Samuel Ojuade

\section{References}

[1] Alahmadi, A. M. (2019). Prevalence of Anxiety Among College and School Students in Saudi Arabia: A systematic review. Journal of Health Informatics in Developing Countries, 13 (1), 1-15.

[2] American Psychological Association. (2013). Diagnostic and statistical manual of mental disorders. 5 th ed. Arlington (VA): American psychiatric association.

[3] Bashir, M., Bashir, A., Mohammed, I., Albaawy, A. H., \& Cumber, S. C. (2019). Predictors and correlates of examination anxiety and depression among high school students taking the Sudanese national board examination in Khartoum state, Sudan: a cross-sectional study. The Pan African Medical Journal, 33-69.

[4] Beck, A. T., Epstein, N., Brown, G., \& Steer, R. A. (1988). An inventory for measuring clinical Anxiety: Psychometric properties. Journal of Consulting and Clinical Psychology, $56 \quad$ (6), 893-897. https://doi.org/10.1037/0022006X.56.6.893.

[5] Daya, P., \& Karthikeyan, G. (2018). Depression, anxiety, stress and its correlates among urban school poing adolescents in Tamilnadu, India. International Journal of Research in Medical Sciences, 6 (8), 2813-2817. 
[6] Jackson-Koku, G. (2016). Beck Depression Inventory. Occupational Medicine, 66 (2), 174-175. https://doi.org/10.1093/occmed/kqv087.

[7] Janosz, M, Briere, F, Galand, B, Pascal, S, Archambault, I, Brault, M, Pagani, L. (2018). Witnessing violence in early secondary school predicts subsequent student impairment. Journal of Epidemiol Community Health, 1 (7), 1117-1123.

[8] Julian, L. J. (2011). Measures of anxiety: State-Trait Anxiety Inventory (STAI), Beck Anxiety Inventory (BAI), and Hospital Anxiety and Depression Scale-Anxiety (HADS-A). Arthritis Care \& Research, 63 (S11), S467-S472. https://doi.org/10.1002/acr.20561.

[9] Kassarnig, V., Mones, E., Bjerre-Nielsen, A., Sapiezynski, P., Lassen, D. D., \& Lehmann, S. (2018). Academic performance and behavioral patterns. EPJ Data Science, 1-7.

[10] Khesht-Masjedi, M. F., Shokrgozar, S., Abdollahi, E., Habibi, B., Asghari, T., Ofoghi, R. S., \& Pazahooman, S. (2019). The relationship between gender, age, anxiety, depression, and academic achievement among teenagers. Journal of Family Medicine and Primary Care, 8 (3), 799-804.

[11] Khurshid, S., Parveen, Q., Yousuf, M., \& Chaudhry, A. (2015). Effects of depression on student's academic performance. Sci. Int (Lahore), 27 (2), 1619-1624.

[12] Krasniqi, N. (2014). Anxiety/Depression and Academic Achievement in Adolescents in Prishtina. Journal of Educational and Social Research, 4 (2), 1-10.

[13] Masjedi, M. F. K. (2018). Prevalence Depression among Adolescents in North of Iran. EC Psychology and Psychiatry, (7 (10)), 738-743.

[14] Mo, Y., \& Tse, V. (2018). The role of high parental expectations in adolescents' academic perfomance and depresion in Hong Kong. Journal of Family Issues, 1 (2), 118.

[15] Oluoch, J. N., Aloka, P. J., \& Odongo, B. C. (2018). est Anxiety Beliefs as Predictor of Students Achievement in Chemistry in Public Secondary Schools in Kenya. International Journal of Psychology and Behavioral Sciences, $8(4), 70-76$.

[16] Pachaiyappan, P., \& Siranjeevi, P. (2018). A study on Depression and Academic Achievement of Higher Secondary
School Students. Scholars Journal of Arts, Humanities and Social Sciences, 6 (3), 1-6.

[17] Pandey, D. (2016). Psychoneuroimmunology of Chronic Illness. Redshine International Press, 191-198.

[18] Pandey, D., \& Shrivastava, P. (2016). Psychometric Properties and Confirmatory Factor Analysis of the Social Support Scale. International Journal of Indian Psychology, 3 (4), 191-198.

[19] Sahu, L., Pandey, D., \& Jha, M. (2016). Self-concept and academic stress among boys and girls students. Indian Journal of Health \& Wellbeing, 7 (5), 540-542.

[20] Sharma, G. (2014). Study of classroom environment, parental education, income \& institution as predictor of students' academic achievement. International Journal of Education and Mangement, 4 (4), 258-262.

[21] Sharma, G., \& Jha, M. (2016). Academic performance in relation to parents' education, institution and sex. Journal of Psychosocial Research, 9 (1), 173-186.

[22] Sharma, G., \& Pandey, D. (2017). Anxiety, Depression and Stress in Relation to Academic Achievement among Higher Secondary School Students. The International Journal of Indian Psychology, 4 (2), 1-9.

[23] Sharma, G., Mitra, M., \& Jha, M. (2015). Clssroom environment as predictor of academic achievement. The Asian Men: An International Journal, 9 (1), 47-51.

[24] Shakir, M. (2014). Academic Anxiety as a Correlate of Academic Achievement. Journal of Education and Practice, $1-9$.

[25] Steinmayr, R., Meibner, A., Weidinger, A., \& Wirthwein, L. (2017). Academic Achievement. San Diego, CA: Oxford University Press.

[26] Sutaria, S., Devakumar, D., Yasuda, S. S., Das, S., \& Saxena, S. (2018). Is obesity associated with depression in children? Systematic review and meta-analysis. Archives of Disease in Childhood, 314-608.

[27] World Health Organization. (2018). Health for the world's adolescents: A second chance in the second decade. Adolescence: A period needing specific attention. Retrieved from http://apps:who.int/adolescent/seconddecade/section2/page2/age-not-the-whole-story.html. 